\title{
Traditional Practices Performed by Nurses During Postpartum Period
}

\author{
Hamide Aygor ${ }^{1}$, Yasemin Durduran ${ }^{2}$, Emel Ege ${ }^{1}$ \\ ${ }^{1}$ Department of Labor and Women Disease Nursing, Faculty of Nursing, Necmettin Erbakan University, Konya, Turkey \\ ${ }^{2}$ Department of Public Health, Meram Medical Faculty, Necmettin Erbakan University, Konya, Turkey \\ Correspondence Author: Hamide Aygor \\ E-mail: hamidedindas@hotmail.com
}

Received: $02.12 .2020 \quad$ Accepted: 20.04 .2021

\begin{abstract}
Objective: In order to provide a quality health service, the awareness of traditional practices of healthcare providers, especially nurses, is as important as the understanding of the illnesses and health perception of those receiving care and their approaches to contemporary and traditional practices, because nurses' own cultural values and beliefs can affect their decisions and attitudes toward the patients. .

Methods: This descriptive study was performed with female nurses with children and working in a university hospital. The sample was not determined by using any special method of selection. The study was completed with the participation of 316 nurses who volunteered to participate in the study. The participation rate was $82 \%$. Data were collected from October 2018 to April 2019 by using a survey form developed by the researchers based on the literature

Results: Of the nurses, $91.5 \%$ thought traditional practices were important but $8.5 \%$ thought that such practices were unimportant to prevent/ resolve health-related problems. The most common first three practices that the nurses implemented to prevent puerperal fever included fortieth-day baths (44.3\%), praying (37.3\%), and not staying home alone (28.2\%).

Conclusion: It is important for nurses to be aware of their viewpoints against traditional practices as to understanding transcultural care and providing service in this direction.
\end{abstract}

Keywords: Nurse, postpartum period, traditional practices.

\section{INTRODUCTION}

Culture is defined as "values, beliefs, manners and customs learned, shared, and passed down from generation to generation by a group of people" (1). It shapes attitudes towards health, health beliefs and behaviors. Today, healthrelated traditions that live and are kept live in Turkey are the product of a vibrant and rich cultural synthesis manifested by civilizations settled in Anatolia. Within this cultural heritage, postpartum practices occupy a very significant place $(2,3)$.

Postpartum period is a duration referring to various cultural beliefs and values in every country in the world. Perceptions and practices regarding this period vary from culture to culture, but are implemented to protect mother and her baby from all kinds of diseases and troubles. Turkey is a country where diverse civilizations have been established since ancient times. For this reason, it has a rich culture. This, in particular, has formed a multicultural populational structure, which has raised the issue of providing satisfactory care in cultural terms. Consequently, the meaning of the postpartum period in the society served by nurses has become more important in nursing care interventions as well as the identification of cultural practices for this period, and cultural barriers to receiving healthcare during this period. For this reason, understanding cultural beliefs and values during the care period has an important role to play in making clinical nursing care decisions and developing care plans $(4,5)$.

It is necessary for nurses to, first of all, comprehend their own attitudes towards traditions and practices in order for them to deliver transcultural care. Culture can influence people's opinions, decisions and actions in certain ways. For this reason, nurses' own cultural values and beliefs can consciously or unconsciously influence their decisions, attitudes and practices regarding patient care. Moreover, self-awareness can be a starting point for nurses to understand women culturally. Thus, they can identify sociocultural differences between patients and themselves, become attentive to such differences and take such characteristics into consideration when delivering care (4-6). Based on this premise, this study was carried out to identify traditional practices followed 
by nurses for themselves, who are expected to provide transcultural care during the postpartum phase of patients.

\section{METHODS}

\subsection{Research Model}

This research is a descriptive type.

\subsection{Study Universe and Group}

The population of the study was comprised of female nurses who had children and served at a hospital of a Faculty of Medicine in Konya province, Turkey. Participation in this study was voluntary. The sample was not determined by using any special method of selection. The aim was to reach at least $80 \%$ of all nurses. The study was completed with the participation of 316 nurses who volunteered to participate in the study. The participation rate was $82 \%$.

\subsection{Data Collection and Data Collection Tools}

Data were collected from October 2018 to April 2019 by using a survey form developed by the researchers based on the literature (7-9). The Survey Form included 15 questions inquiring sociodemographic characteristics and traditional practices. The survey forms were handed out to the nurses, and they were asked to fill the forms out. It took 10-15 minutes to fill the survey forms.

\subsection{Ethical Approval}

Ethics committee approval was obtained from the Noninvasive Clinic Ethical Committee of the Medical Faculty at Necmettin Erbakan University (Decision no.72/2018). Institution approval of the study was obtained from the institution in which the study is conducted and verbal consent was obtained from the nurses.

\subsection{Data Analysis}

The analyses of the data obtained in the study were conducted using SPSS 20 statistical analysis program (Chicago, IL, USA). Number, percentage, mean and standard deviation were used to analyze the data. The significance level was accepted as $\mathrm{p}<.05$

\subsection{Limitations and Generalizability of the Study}

The findings of our study are limited to the hospital where the study was conducted and so cannot be generalized to the other regions of Turkey. The study was conducted on nurses who were all from the same culture, which was a limitation of the study. It was another limitation of the study that the nurses responded to the questions by recalling past knowledge.

\section{RESULTS}

The average age of the 316 nurses (82\%) who participated in the study was $35.9 \pm 7.05$ of these nurses, $94.9 \%$ were married, $57.6 \%$ were four-year college graduates, and $83.9 \%$ lived in the Central Anatolia region for the most part of their lives. The mean number of the pregnancies of the nurses was 2.06 \pm 1.13 , and $59.2 \%$ had two or more living children (Table 1 ).

Table 1. Sociodemographic and obstetric characteristics of nurses (n:316)

\begin{tabular}{|c|c|c|}
\hline Characteristics & Median (Min.- Max.) & $\bar{x} \pm S S$ \\
\hline Age & $36.0(22-49)$ & $35.9 \pm 7.05$ \\
\hline Marriage age & $23.5(17-37)$ & $23.7 \pm 3.34$ \\
\hline Duration of marriage & $10.0(1-35)$ & $11.8 \pm 7.53$ \\
\hline \multirow[t]{2}{*}{ Number of pregnancy } & & $2.06 \pm 1.13$ \\
\hline & $\mathrm{n}$ & $\%$ \\
\hline \multicolumn{3}{|l|}{ Marital Status } \\
\hline Married & 300 & 94.9 \\
\hline Single & 16 & 5.1 \\
\hline \multicolumn{3}{|l|}{ Educational status } \\
\hline High School & 42 & 13.3 \\
\hline Two-year college & 58 & 18.4 \\
\hline Four-year college & 182 & 57.6 \\
\hline Post graduate & 34 & 10.8 \\
\hline \multicolumn{3}{|c|}{ Evaluating monthly income } \\
\hline Good & 115 & 36.4 \\
\hline Middle & 191 & 60.4 \\
\hline Bad & 10 & 3.2 \\
\hline \multicolumn{3}{|l|}{ Family type } \\
\hline Nuclear family & 301 & 95.3 \\
\hline Extended family & 15 & 4.7 \\
\hline \multicolumn{3}{|c|}{ Number of Children Living } \\
\hline$<2$ & 129 & 40,8 \\
\hline$\geq 2$ & 187 & 59.2 \\
\hline \multicolumn{3}{|l|}{ The longest lived place } \\
\hline City & 271 & 85.8 \\
\hline Village/Town & 46 & 14.2 \\
\hline \multicolumn{3}{|c|}{$\begin{array}{l}\text { The longest lived geographical } \\
\text { region }\end{array}$} \\
\hline Aegean Region & 20 & 6.3 \\
\hline Mediterranean Region & 22 & 7.0 \\
\hline Black Sea Region & 7 & 2.2 \\
\hline Marmara Region & 2 & 0.6 \\
\hline Central Anatolia Region & 265 & 83.9 \\
\hline
\end{tabular}

Of the nurses, $91.5 \%$ thought traditional practices were important but $8.5 \%$ thought that such practices were unimportant to prevent/resolve health-related problems. The most common first three practices that the nurses implemented to prevent puerperal fever included fortiethday baths (44.3\%), praying (37.3\%), and not staying home alone (28.2\%). In order to increase breast milk supply, their practices involved consuming molasses/halva/sweet food items (42.4\%), consuming crashed wheat pilaf/kisir (traditional 
crashed wheat salad)/lentils (38.6\%) and consuming onions (29.4\%), in the order of frequency (Table 2).

Table 2. Traditional practices that nurses implemented for themselves during their own postpartum period. (n:316)

\begin{tabular}{|c|c|c|c|c|}
\hline \multirow{2}{*}{ Traditional practices } & \multicolumn{2}{|l|}{ Yes } & \multicolumn{2}{|l|}{ No } \\
\hline & $\mathrm{n}$ & $\%$ & $\mathrm{n}$ & $\%$ \\
\hline \multicolumn{5}{|l|}{ Practices to prevent puerperal fever } \\
\hline Taking a fortieth-day bath & 140 & 44.3 & 176 & 55.7 \\
\hline Praying & 118 & 37.3 & 198 & 62.7 \\
\hline Not staying home alone & 89 & 28.2 & 227 & 71.8 \\
\hline $\begin{array}{l}\text { Placing a copy of Koran in puerperal } \\
\text { women's room }\end{array}$ & 73 & 23.1 & 243 & 76.9 \\
\hline $\begin{array}{l}\text { Tying a red scarf or ribbon on the head } \\
\text { of the woman }\end{array}$ & 71 & 22.5 & 245 & 77.5 \\
\hline Avoiding attending a funeral & 47 & 14.9 & 269 & 85.1 \\
\hline $\begin{array}{l}\text { Not allowing two puerperal women to } \\
\text { visit each other }\end{array}$ & 41 & 13 & 275 & 87 \\
\hline $\begin{array}{l}\text { A menstruating woman's avoiding } \\
\text { visiting a puerperal woman }\end{array}$ & 34 & 10.8 & 282 & 89.2 \\
\hline $\begin{array}{l}\text { Leaving a sharp tool like a sickle or a } \\
\text { knife in puerperal women's } \\
\text { room }\end{array}$ & 26 & 8.2 & 290 & 91.8 \\
\hline
\end{tabular}

\section{Practices to increase breast milk supply}

\begin{tabular}{lllll}
$\begin{array}{l}\text { Consuming molasses, halva, and sweet } \\
\text { food items }\end{array}$ & 134 & 42.4 & 182 & 57.6 \\
\hline Consuming crashed wheat pilaf/kısır & 122 & 38.6 & 194 & 61.4
\end{tabular}

(traditional crashed wheat

salad)/lentil

\begin{tabular}{|c|c|c|c|c|}
\hline Consuming onion & 93 & 29.4 & 223 & 70.6 \\
\hline $\begin{array}{l}\text { Drinking puerperal woman sherbet (a } \\
\text { type of sweet drink } \\
\text { prepared specifically for the sake of a } \\
\text { puerperal woman) }\end{array}$ & 86 & 27.2 & 230 & 72.8 \\
\hline Consuming quince compote & 68 & 21.5 & 248 & 78.5 \\
\hline
\end{tabular}

\begin{tabular}{|c|c|c|c|c|}
\hline $\begin{array}{l}\text { Other traditional practices } \\
\text { Puerperal women's avoiding having sex } \\
\text { for } 40 \text { days }\end{array}$ & 245 & 77.5 & 71 & 22.5 \\
\hline $\begin{array}{l}\text { Puerperant women's celebrating the } \\
\text { 40th day of delivery }\end{array}$ & 148 & 46.8 & 168 & 53.2 \\
\hline $\begin{array}{l}\text { Wrapping puerperant women's } \\
\text { abdomen }\end{array}$ & 126 & 39.9 & 190 & 60.1 \\
\hline Avoiding doing housework & 61 & 19.3 & 255 & 80.7 \\
\hline Avoiding leaving the house for 40 days & 59 & 18.7 & 257 & 81.3 \\
\hline $\begin{array}{l}\text { Traditional practices implemented to } \\
\text { prevent/resolve } \\
\text { health-related problems }\end{array}$ & 289 & 91.5 & 27 & 8.5 \\
\hline
\end{tabular}

When the nurses were asked about what they would initially do in any health-related problem, $67.7 \%$ stated that they presented to a health institution, $27.8 \%$ stated that they tried to solve it using certain traditional practices that they knew, and $4.4 \%$ stated that they tried to cure it on their own.

\section{DISCUSSION}

Every culture has their own beliefs and practices. A nursing care practice that ostracizes cultural characteristics negatively influences patients' sense of trust in and cooperation with nurses. Nurses should be mindful of cultural differences, so that people who have influenced their lives according to cultural values and spiritual beliefs can be supported with high quality and professional nursing care. In order to do that, first of all, nurses should be aware of their own cultural values and beliefs. Otherwise, they will tend to ignore cultural characteristics and orientations of people receiving care by making decisions according to the values and norms of their (the nurses') own culture in their decisions when providing care.

The average age of the 316 nurses involved in the study was $35.9 \pm 7.05$. It can be said that the nurses were in their midadulthood. The most important function of the idea of self in mid-adulthood, according to Erikson's theory of Stages of Psychosocial Development, is productivity and creativity, especially in technical and artistic fields (10). Accordingly, given their ages, it can be said that the nurses had matured in terms of professional knowledge and experience and were at a stage where they could transfer such knowledge and experience to patient care.

The nurses' opinions about traditional practices implemented to prevent/resolve health-related problems showed that 91.5\% thought such practices were important and $8.5 \%$ thought that they were unimportant. Similarly, Kaewsarn, Moyle, and Creedy (8) reported that almost half of nurses (48.92\%) cared about traditional practices implemented during the postpartum period. In another study, Karakuş, Babadağ, Abay, Akyar, and Çelik (11) reported that nurses were aware of the importance of cultural differences in health care. Similarly, Yalçıner and Çam (12) reported that $43.1 \%$ of nurses considered non-harmful traditional practices favorably. It can be said that nurses were mindful of traditional practices.

Culture influences every aspect of human life. Such practices can be implemented even in the most important parts of women's lives and when they are very sensitive, like in the postpartum period. It has been reported in many studies that mothers carry out different practices during the postpartum period and attach great importance to such practices to protect their health and the health of their babies $(13,14$, 15). Particularly important for transcultural treatment in this context is customs, beliefs and values of nurses themselves. In this study, the nurses reported their own traditional practices that they performed during the postpartum period. Among them, the most common first three implemented by the nurses to prevent puerperal fever included fortiethday baths $(44.3 \%)$, praying $(37.3 \%)$, and not staying home alone $(28.2 \%)$. Among the practices that were carried out 
to increase breast milk supply, consuming molasses/halva/ sweet food items (42.4\%), consuming crashed wheat pilaf/ kisir (traditional crashed wheat salad)/lentils (38.6\%) and consuming onions (29.4\%) were prominent. Similarly, the idea that "the baby and woman who have not completed forty days after childbirth are not left alone and not taken out of the house for forty days" (64.1\%) were among the practices aimed at preventing women's puerperal fever in a study conducted in Karaman, Turkey (16). In the study of Kaewsarn et al. (8), nurses stated that there should be a balanced diet to maintain milk supply during the postpartum period. In that study, the nurses stated that people should consume fish $(98.9 \%)$, eggs (98.7\%), buffalo meat (20\%), vegetables (97.6\%), red pepper (chili pepper, 54.9\%), and durian (a tropical fruit, 62.9\%). In the study by Tien (17), nurses and mothers stated that they believed postpartum traditional practices are a universal phenomenon, and traditional practices are effective in regaining physical health.

\section{CONCLUSION}

It was found that there were nurses who thought that traditional practices during the postpartum period were important, and they implemented such practices personally. Nurses need to be conscious of their own attitudes towards traditional practices, appreciate transcultural care and deliver services in this way. In this context, it is recommended to incorporate transcultural nursing courses into undergraduate education. In addition to raising nurses' awareness of transcultural care, their cultural competence should be supported by in-service training programs after graduation.

Conflict of Interest: The authors have no conflict of interest to declare.

Financial Disclosure: The authors declared that this study has received no financial support.

Author Contributions: Concept - H.A.,Y.D., E.E.; Design - H.A.,Y.D., E.E.; Supervision - H.A.,Y.D., E.E.; Resources H.A.,Y.D., E.E.; Materials - H.A.,Y.D., E.E.; Data Collection and/ or Processing - H.A.; Analysis and/or Interpretation - H.A., ; Literature Search - H.A; Writing Manuscript - H.A; Critical Review - H.A.,Y.D., E.E.

\section{REFERENCES}

[1] Bulduk S, Tosun H, Ardıç E. Measurement properties of Turkish intercultural sensitivity scale among nursing students. Turkiye Klinikleri J Med Ethics 2011;19(1):25-31
[2] Foronda, CL. A concept analysis of cultural sensitivity. J Transcult Nurs 2008;19(3): 207-212.

[3] Kahraman N, Sancar O. Cultural sensitivity of health employees. International Peer-Reviewed Journal of Communication and Humanities Research 2017;15:107-131.

[4] Ceylantekin Y, Öcalan D. The cultural awareness of the nursing students and their ideas about transcultural nursing. Gümüşhane University Journal of Health Sciences 2016;5(4):45-53.

[5] Egelioğlu Cetişli N, Işık G, Özgüven Öztornacı B, Ardahan E, Özgürsoy BN, Top ED, Ünsal Evdal E. Intercultural sensitivity of nursing students according to their empathy level. İzmir Kâtip Çelebi University Faculty of Health Science Journal 2016; 1(1): 27-33.

[6] Öztürk E, Öztaş D. Transcultural nursing. Batman University Journal of Life Sciences 2012; 1(1): 293-300.

[7] Gökduman M, Balkaya NA. Traditional practices of mothers to improve breast milk production during postpartum 6 months. Meandros Medical and Dental Journal 2013; 14(1): 31-41.

[8] Kaewsarn P, Moyle W, Creedy D. Thai nurses' beliefs about breastfeeding and postpartum practices. J Clin Nurs 2003; 12(4): 467-475.

[9] LafCI D, Erdem E. Traditional practises regarding mother and infant care of 15-49 year old married women in the postpartum period. Gaziantep Medical Journal 2014; 20(3): 226-236.

[10] Taşkıntuna N. Erikson's psychosocial development theory. Current Clinical Psychiatry 2008; 9-16.

[11] Karakuş Z, Babadağ B, Abay H, Akyar I, Çelik S. Nurses' views related to transcultural nursing in Turkey. International Journal of Caring Sciences 2013; 6(2): 201-207.

[12] Yalçıner N, Çam MO. The opinions about transcultural care of nurses working in psychiatry. J Psy Nurs 2015; 31(3): 20-36.

[13] Alp Yılmaz F, Şener Taplak A, Polat S. Individual applications of Turkish lactating women to increase the their breastmilk production. Journal of Current Researches on Health Sector 2018; 8(2): 121-134.

[14] Altuntug K, Anık Y, Ege E. Traditional practices of mothers in the postpartum period: evidence from Turkey. Afr J Reprod Health 2018; 22(1): 94-102.

[15] Koçak DY, Akarsu Höbek R. Determining of the traditional practices for mother and baby care at women's postpartum period in Turkey (Anatolian sample). Journal of Current Researches on Health Sector 2018; 8(2):145-156.

[16] Yalçın H. Traditional practices related to pregnancy, childbirth, puerperium and baby care (Karaman example). Journal of Child Health and Diseases 2012; 55(1):19-31.

[17] Tien, SF. Nurses' knowledge of traditional Chinese postpartum customs. Western Journal of Nursing Research 2004: $26(7), 722-732$. 